\title{
Intralesional Sclerotherapy Using Absolute Alcohol for Management of Haemangioma
}

\author{
Sachraswaty R. Laidding ${ }^{1}$, Marthin S.W. ${ }^{2}$, Fonny Josh ${ }^{1}$, Prihantono Prihantono,"* \\ ${ }^{1}$ Plastic, Reconstructive, and Aesthetic Surgery Division, Faculty of Medicine, Hasanuddin University, Makassar, Indonesia \\ ${ }^{2}$ Surgery Division, Faculty of Medicine, Hasanuddin University, Makassar, Indonesia \\ *Corresponding author: prihantono.md@gmail.com
}

\begin{abstract}
Background. Soft tissue haemangiomas are non-malignant lesions; some optional management could be chosen. Sclerotherapy by the sclerosing agent has been used in the management of haemangiomas. Method. We performed intramucous embolization of haemangioma in three patients. The procedure was conducted under general anesthesia. The sclerosing agent used was an absolute alcohol $98 \%$ at a dose of $10 \mathrm{ml}, 5 \mathrm{ml}$, and $2 \mathrm{ml}$ in each patient. After the procedure, they received analgesics and antibiotic therapy. One month after the sclerosing treatment, all patients underwent reconstruction surgery. Result. The evaluation was performed several days after the injection. The pain and tissue swelling occurs in the first week and gradually decreased each day until the second week. The final result was evaluated after the patient undergone reconstruction surgery. All patient's parent were satisfied. Conclusions. The intralesional sclerotherapy of haemangioma using absolute alcohol proved to be a safe, cheap and effective method to achieve preoperative devascularization of hemangiomas
\end{abstract}

Keywords: haemangioma, absolute alcohol, sclerosing agent, intramucous injection, reconstruction surgery

Cite This Article: Sachraswaty R. Laidding, Marthin S.W., Fonny Josh, and Prihantono Prihantono, "Intralesional Sclerotherapy Using Absolute Alcohol for Management of Haemangioma.” American Journal of Medical Sciences and Medicine, vol. 5, no. 4 (2017): 67-70. doi: 10.12691/ajmsm-5-4-1.

\section{Background}

Soft tissue haemangiomas are non-malignant lesions that can be conveniently categorized as capillary, venous and cavernous [1,2]. Management of haemangiomas of the head and neck poses too many problems that one-set solution naturally becomes impossible [3,5].

Consideration must be given to the type of the lesion, the depth of the lesion, the relationship of the lesion to adjacent vital structures and the patient's age. Local infarction and thrombosis will result in the spontaneous resolution of a haemangioma.

Several modes of treatment may be considered, such as radiotherapy, electrocoagulation, surgery, cryosurgery, carbon dioxide snow, silver nitrate and sclerosing solutions. Sclerosing solutions have been used in the management of haemangiomas for more than 100 years. Many different sclerosing agents are used [6,7]. Among these are sodium tetradecyl sulfate (3\% sterol), sodium morrhuate, sodium citrate, monoethanolamine oleate, invert sugar, boiling water and sodium phyllite $[8,9,10]$. This case report of a haemangioma of the right upper lip, successfully treated with an injection of absolute alcohol (98\%) continued with reconstruction surgery.

\section{Cases Report}

We have 3 cases about 17 years old female (patient A) and five years old girl patients (patient B), and two years old male patient (patient C) presented with a reddish swelling at upper lips since childhood, which gradually increased in size. There was a history of pain, easily bleeding, abnormality of speech.

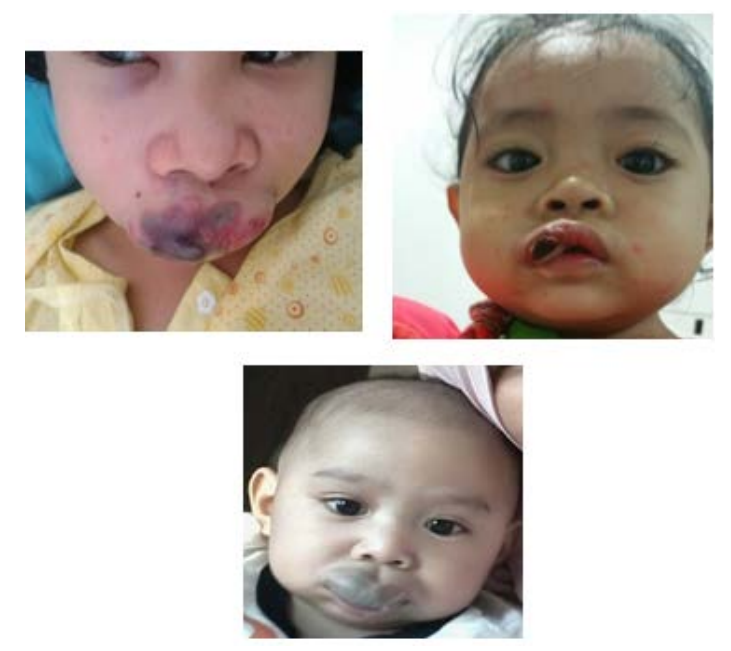

Figure 1. Showing the lesion on each patient

From the physic examination, patient A came with localized dome-shaped red swelling measuring approximately $7 \mathrm{~cm}$ $\times 3 \mathrm{~cm}$ present in the upper lips, patient B with $3 \mathrm{~cm} \times 2$ $\mathrm{cm}$, and patient $\mathrm{C}$ with $4 \mathrm{~cm} \mathrm{x} 2 \mathrm{~cm}$. Borders of The swelling was well defined, and it extended anteroposteriorly from lips to the oral mucous. There was no visible pulsation. On palpation, it was soft to firm in consistency, immobile, and nontender. [Figure 1] 
Based on the history and clinical features, a working diagnosis with haemangioma was arrived following which necessary radiologic investigations were carried out. We perform upper lips Doppler ultrasound on patient A, and it revealed an ill-defined as heterogenous hypervascularization lesion with well-defined border, irregular edge on soft tissue, not seen the feeder vessel.[Figure 2].
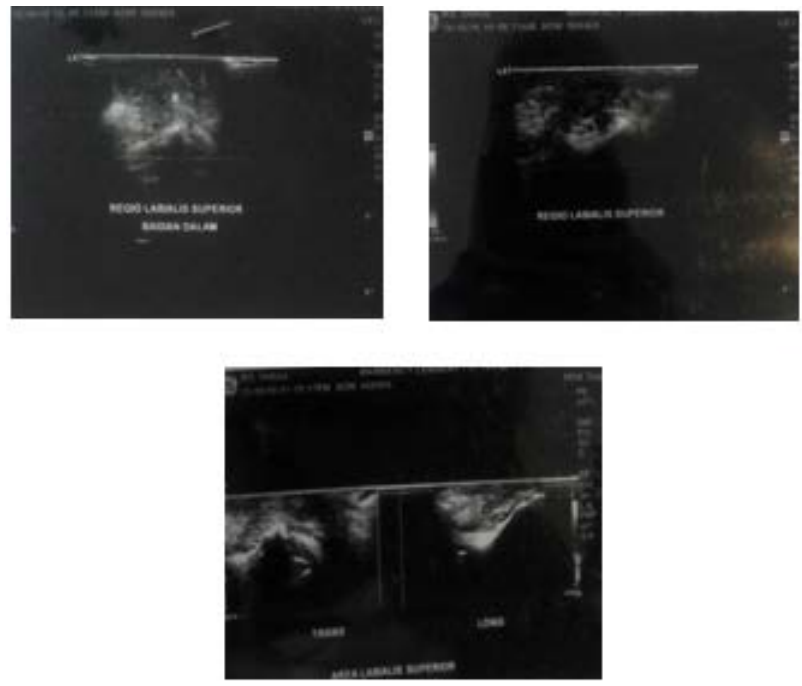

Figure 2. Patient A's Doppler Ultrasound showing hypervascularization lesion.

Considering the provisional diagnosis, management with an intramucous injection of absolute alcohol (ethanol 98\%) was decided with the consent of the patient. All procedures were performed at operation room, and we use general anesthesia with Total Intra Vein Anaesthesia (TIVA), intramucous injection of absolute alcohol was given using a 25 gauge needle with each dose $10 \mathrm{ml}$ for patient $\mathrm{A}, 5 \mathrm{ml}$ for patient $\mathrm{B}$ and $2 \mathrm{ml}$ for patient $\mathrm{C}$
[Figure 3]. After the procedure, the patients were observed in their room.

The first day after the procedure, all patients presented with painful diffuse enlargement of the lips which appeared erythematous with multiple ulcers with the tender necrotic floor in the injected sites. We haven't received any report of systemic symptoms, and their vital signs were usual.

\section{Table 1. THE PROCEDURE}

1. Patient laid supine under general anesthesia (total intervein anesthesia) 2. Disinfection and dropping procedure

3. Clamp the upper lips

4. Infiltrate alcohol solution intramucous.

5. Clean up the surgical site

6. Patient stay intubate for 1 hour

7. After an hour, the anesthesia extubate and woke up the patient

It was clinically diagnosed as a severe local inflammatory reaction to the sclerosing agent and was managed with analgesic (paracetamol) and antibiotic (cefadroxil). On the second day, all patients seem better, decrease in pain, usual vital sign and permitted to home.

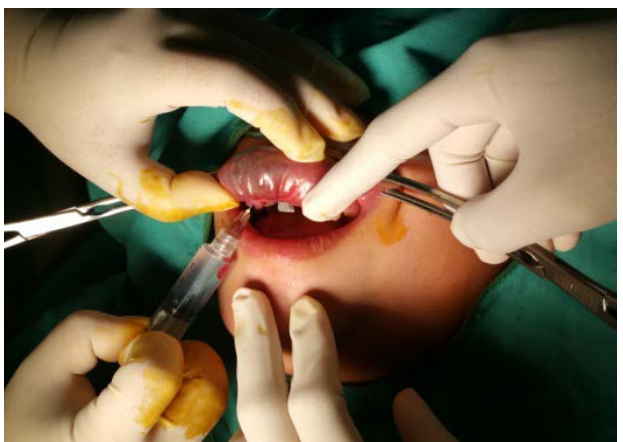

Figure 3. The injection process

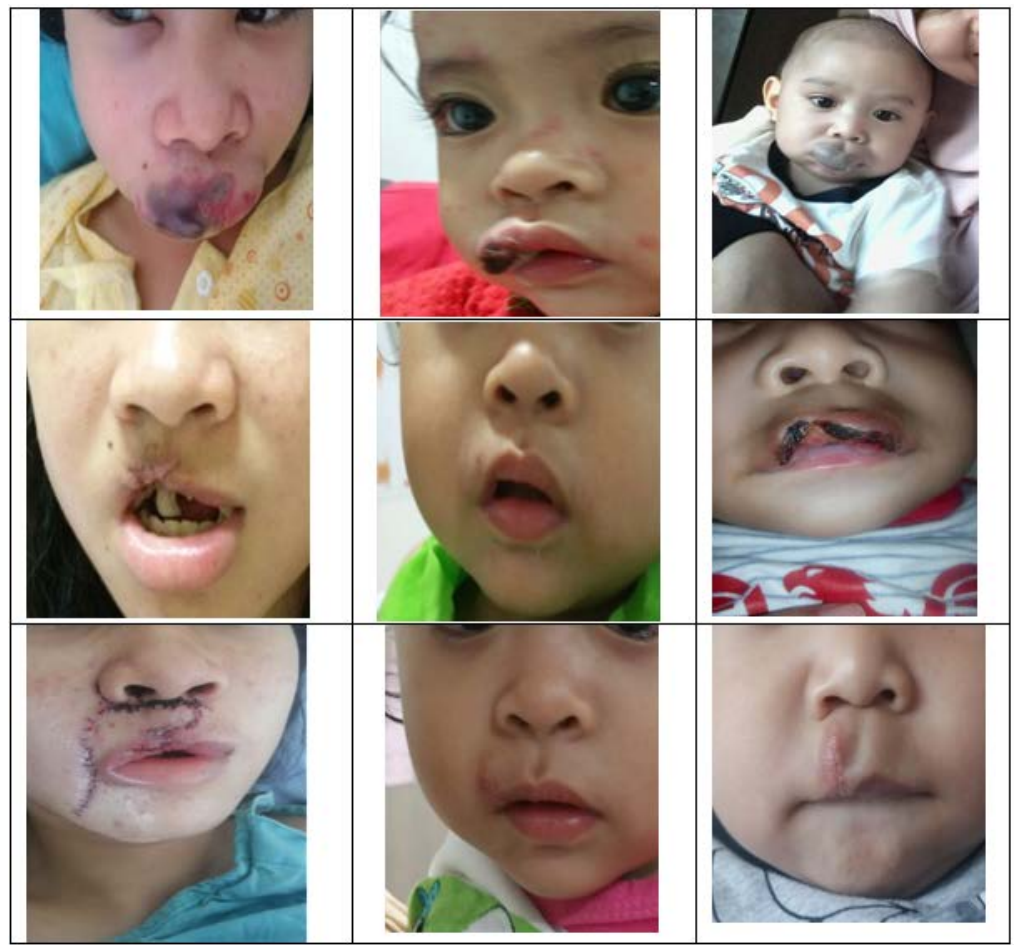

Figure 4. Show the lesion before (upper column), after (middle column) sclerosing agent injection about two weeks and after reconstruction surgery (lower column) 
Patients were recalled every three days on a clinic for review and wound care, one week after the therapy patient fell the pain, and the swelling was gradually decreased, at the second week they did not feel any pain, and the swelling look healed with some necrotic and fibrotic area. One month after the injection, we perform reconstruction surgery to all patients [Figure 4].

\section{Discussion}

The International Society for the Study of Vascular Anomalies Classification divides vascular anomalies into two primary biological categories: (1) Vasoproliferative or vascular neoplasms and (2) Vascular Malformations $[11,12]$. In our case, the lesion was present in the lips since childhood, and it was gradually increasing in size which can be correlated with the features of haemangioma.

Lesion at the lips causes discomfort and potentially severe clinical problems such as recurrent bleeding, biting of the lesion, pain, and difficulty with speaking, mastication or deglutition. Our patient gave a history of trouble with speaking and occasional biting of the lesion.

Doppler ultrasound revealed an ill-defined heterogenous hypervascularization lesion with well-defined border, irregular edge on soft tissue, not seen the feeder vessel. MRI may be helpful to further characterize sonographic findings and determine the extent of broader lesions for planning medical, interventional, and surgical therapy, but on our case, we not used it for some reasons.

Treatment of benign vascular lesions includes surgery, systemic corticosteroids, interferon- $\alpha$, laser, embolization, sclerotherapy, cryotherapy, and radiation. The procedure employed in the present case was sclerotherapy which is the best compliment to subsequent surgery. Advantages of the sclerosing agent are that it is simple, inexpensive, readily available, hospitalization not required and cause no blood loss. Disadvantages are postoperative pain and burning sensation, anaphylactic reaction, tissue necrosis, and sloughing (4\%) and airway compromise (1\%).

The pain which is usually short-lived and subsided within 24 hours. This occurs when the injection is given below the dentate line, or the sclerosant spreads below the dentate line. Typically this pain can be managed by topical painkillers or analgesics. Complication of bleeding can occur by accidentally puncturing the artery and can be stopped by pressure gauze. Delayed bleeding may occur after 7-14 days if too much solution is injected or by wrongly injecting the mucosa instead of beneath it.

Other complications include allergic reactions, psychogenic reactions (collapse, vasovagal shock), infection, incontinence and very rarely a sepsis could occur. We believe absolute ethanol is probably the most useful agent. It induces permanent obliteration of the vessel lumen with the least chance of recanalization because it denatures blood protein, denudes the vascular wall of endothelial cells and fractures the vessel walls.

However, ethanol is a liquid solution, and when injected with too high a force there is the propensity to spread into usual adjacent vascular territories producing ischemia and necrosis in such areas as the skin and nerves $[13,14]$.
The mean amount was at least three times greater than the one used with ethylcellulose. For instance, Study used a volume of ethanol up to $1 \mathrm{ml} / \mathrm{kg}$ of body weight. Local and systemic side effects are directly correlated to the amount of injected ethanol. Among the 320 treated patients, both local and systemic complications have been described. The percentage of minor complications such as cutaneous necrosis, fistula, and post-sclerosis surgery was the same as ours $[15,16,17]$.

\section{Conclusion}

The management of vascular lesions is challenging. Though sclerotherapy produces local complications as we encountered in our case, it proves that absolute alcohol as sclerosant to be a safe, cheap and effective for achieving preoperative devascularization of the lesion.

\section{References}

[1] Bahador A, et al. (2008). Effect of submucosal alcohol injection on prolonged rectal prolapse in infants and children. J Indian Assoc Pediatr Surg, 13:11-3.

[2] Chauhan V, Patel K, Anchalia M. (2014). Prospective Comparative study of sclerotherapy by hypertonic saline and absolute alcohol for the treatment of hemorrhoids. Gujarat Med J; 69(1): 82-6.

[3] Chim H, Gosain A. (2014). Vascular Anomalies. Dalam: Grabb and Smith's Plastic Surgery, Seventh Ed. Philadelphia: Lippincott Williams and Wilkins. H. 206-220.

[4] Marler J, Mulliken J. (2010). Current management of hemangiomas and vascular malformations. Clin Plastic Surg, 32: 99-166.

[5] Nafianti S. (2010). Hemangioma Pada Anak. Dalam: Sari Pediatri, 12(3): 204-10.

[6] Parvathidevi, et al. (2013). Case Report: Management of haemangioma with a sclerosing agent. BMI case rep 2013.

[7] Seruga T, Lucev J, Jevsek M. (2013). Treatment of Tongue Cavernous Haemangioma with Direct Puncture and Sclerotization with ethanol. Radiol Oncol; 49(5) 75-9.

[8] Sierre S, Teplisky D, Lipsich J. (2016). Vascular malformations: an update on imaging and management. Arch Agent Pediatr; 114(2):167-76.

[9] Sitra B, et al. (2015). A New Venture with Sclerotherapy in an Oral Vascular Lesion. J Basic and Clin Pharma; 6(1): 40-3.

[10] Smithers J, Fishman S. (2010). Vascular Anomalies. Dalam: Ashcraft's Pediatric Surgery. Fifth Ed. Philadelphia: Elsevier Inc. H. 983-8.

[11] Zhang J, Li HB, Zhou SY, Chen KS, Niu CQ, Tan XY, Jiang YZ, Lin QQ. Comparison between absolute ethanol and bleomycin for the treatment of venous malformation in children. Experimental and therapeutic medicine. 2013 Aug 1;6(2):305-9.

[12] Heit JJ, Do HM, Prestigiacomo CJ, Delgado-Almandoz JA, English J, Gandhi CD, Albuquerque FC, Narayanan S, Blackham KA, Abruzzo T, Albani B. Guidelines and parameters: percutaneous sclerotherapy for the treatment of head and Neck venous and lymphatic malformations. Journal of neurointerventional surgery. 2016 Jan 22: Neurosurg-2015.

[13] Das A, Sengupta A, Ghosh D, Bose D, Dhara S, Sengupta A. Intralesional Sclerotherapy with Polidocanol in the Management of Head and Neck Vascular Lesions. Bengal Journal of Otolaryngology and Head Neck Surgery. 2016 Dec 18; 24(3): 136-40.

[14] Horbach SE, Lokhorst MM, Saeed P, Rothová A, van der Horst CM. Sclerotherapy for low-flow vascular malformations of the head and neck: A systematic review of sclerosing agents. Journal of Plastic, Reconstructive \& Aesthetic Surgery. 2016 Mar 31; 69(3): 295-304.

[15] Seruga T, Lucev J, Jevsek M. Treatment of tongue cavernous haemangioma with direct puncture and sclerotization with ethanol. Radiology and oncology. 2015 Mar 1; 49(1): 75-9. 
[16] Da Silva WB, Ribeiro AL, de Menezes SA, Pinheiro JD, de Melo Alves-Junior S. Oral capillary hemangioma: A clinical protocol of diagnosis and treatment in adults. Oral and maxillofacial surgery. 2014 Dec 1; 18(4): 431-7.
[17] Holzman RS. Vascular Anomalies. InPediatric Anesthesiology Review 2017 (pp. 615-624). Springer International Publishing. 